\title{
Environmental condition to fish culture using floating cage in Manalu Cluster, Sangihe Islands Regency
}

\section{Kondisi lingkungan perairan untuk budi daya ikan dengan sistem karamba jaring apung di Perairan Klaster Manalu, Kabupaten Kepulauan Sangihe}

\author{
Inayati H.G.M Lano ${ }^{1}$, Edwin L.A. Ngangi ${ }^{2} *$, and Markus T. Lasut ${ }^{2}$ \\ ${ }^{1}$ Program Studi Ilmu Perairan, Program Pascasarjana Universitas Sam Ratulangi. Jln. Kampus Unsrat Kleak, \\ Manado 95115, Sulawesi Utara, Indonesia. \\ ${ }^{2}$ Fakultas Perikanan dan Ilmu Kelautan, Universitas Sam Ratulangi. Jl. Kampus Unsrat Bahu, Manado 95115, \\ Sulawesi Utara, Indonesia. \\ *E-mail:edwin.ngani@unsrat.ac.id
}

\begin{abstract}
Manalu and it surroundings cluster is a zone which is designated as a development center for agropolitan and minapolitan region and as a marine and coastal aquaculture center which include Manalu Bay, South Tabukan sub-district, South East Tabukan sub-district, and Center Tabukan sub-district. Hangke, Sensahang/Ensahange, Talawe, Kalagheng, Mutung and Bembiha areas are included in this cluster, although no research has been conducted to study this area. Data collected include water quality parameters, data about convenience and risk factor. Data about convenience and risk factor was collected by interview with persons who consider as those who know best about the site and do marine culture for living. Water quality parameters was collected by doing measurement on salinity, temperature, disolved oxygen, visibility, $\mathrm{pH}$, water depth and current velocity in 4 representative areas. The collected data show that convenience factor was high and risk factor was low. Due to low water depth and low visibility, area 1and 2 was not recomended for futher development for marine culture with floating cage construction. Area 3 and 4 can be recomended for futher development because data result show good value.
\end{abstract}

Keywords: agropolitan; minapolitan; aquaculture; floating cage; Manalu, Sangihe Islands.

Abstrak: Klaster Manalu dan sekitarnya merupakan zona yang diperuntukkan untuk pusat pengembangan kawasan agropolitan dan minapolitan, dan pusat budi daya pantai dan laut di mana meliputi Teluk Manalu, Kecamatan Tabukan Selatan, Kecamatan Tabukan Timur, dan Kecamatan Tabukan Tengah. Perairan Hangke, Sensahang/Ensahange, Talawe, Kalagheng, Mutung, dan Bembiha masuk dalam klaster ini, meskipun belum ada penelitian dilakukan untuk mengkaji hal tersebut. Data yang dikumpulkan meliputi parameter kualitas air, faktor kenyamanan, dan faktor risiko. Data faktor kenyamanan dan risiko dikumpulkan menggunakan teknik wawancara kepada masyarakat, yang mengetahui tentang keberadaan daerah tersebut. Parameter kualitas air dikumpulkan dengan cara melakukan pengukuran terhadap salinitas, suhu, oksigen terlarut, kecerahan, $\mathrm{pH}$, kedalaman, dan kecepatan arus pada 4 lokasi yang dipilih. Hasil analisis menunjukkan, bahwa faktor kenyamanan berada pada tingkatan tinggi dan faktor risiko berapa pada tingkatan rendah. Dalam hal kondisi perairan, karena kedalaman dan kecerahan rendah pada Lokasi 1 dan 2, maka lokasi tersebut tidak dianjurkan untuk dilakukan pengembangan budi daya laut menggunakan kurungan jaring apung (KJA). Lokasi 3 dan 4 dapat dianjurkan untuk dilakukan pengembangan karena hasil pengamatan menunjukkan nilai yang "baik".

Kata-kata kunci: agropolitan; minapolitan; budi daya perairan; karamba jaring apung; Manalu; Kepulauan Sangihe.

\section{PENDAHULUAN}

Budi daya laut yang menggunakan keramba jaring apung (KJA) memiliki beberapa manfaat, salah satunya, yaitu membuka lapangan pekerjaan baru bagi masyarakat pesisir berekonomi lemah, khususnya nelayan kecil. Diharapkan melalui usaha ini dapat meningkatkan penghasilan, karena biaya produksi untuk kegiatan ini relatif kecil. Kegiatan KJA dapat memanfaatkan perairan laut umum, yang tidak terpakai di lokasi sekitar tempat tinggal pembudi daya sehingga tidak memerlukan biaya untuk menyewa atau membeli lahan budi daya. Selain itu, untuk keperluan pakan, biasanya, hanya menggunakan ikan sisa hasil tangkapan yang kurang memiliki nilai jual.

Berdasarkan data Dinas Kelautan dan Perikanan, Kabupaten Kepulauan Sangihe, bahwa pada tahun 2016, produksi perikanan budi daya laut sebesar 123 ton dengan nilai jual sekitar 
Rp121.435.800.000,-. Walaupun demikian, produksi ikan laut yang dibudidayakan dengan sistem KJA kontribusinya hanya sebesar $10,38 \%$ atau 12,77 ton. Usaha budi daya perikanan KJA ini, umumnya, dilakukan oleh pembudi daya skala kecil. Produksi biota yang dibudi daya, yaitu udang lobster sebesar 10,97 ton, ikan kuwe sebesar 1,2 ton, dan ikan beronang sebesar 0,6 ton.

Di sisi lain, perikanan KJA laut, walaupun produksinya masih rendah tetapi telah memberikan cukup kontribusi untuk meningkatkan taraf hidup bagi beberapa kelompok pembudi daya, yang dahulunya adalah nelayan berpenghasilan rendah di Kabupaten Kepulauan Sangihe. Untuk itu, pengembangannya, yang memanfaatkan potensi perairan laut yang luas, diharapkan mampu mengurangi jumlah masyarakat miskin di daerah pesisir dan, secara tidak langsung, dapat meningkatkan pendapatan asli daerah.

Potensi lahan perikanan budi daya laut di Kab. Kep. Sangihe, berdasarkan dokumen RZWP3K tahun 2015, yaitu seluas 5.542,54 Ha (Anonim, 2015). Potensi lahan kerang mutiara berada di 3 lokasi, yaitu Kecamatan Tabukan Selatan Tengah (Pesisir P. Tehang), Kec. Manganitu (Pesisir barat), Kec. Tabukan Selatan Tengah (Selat P. Batuwingkung) dengan luas 86,05 Ha; ikan kerapu tersebar di 6 lokasi, yaitu Kec. Manganitu Selatan

Tabel 1. Kesesuaian parameter perairan untuk budi daya ikan laut dalam KJA (Heriansah and Anggriawan, 2015)

\begin{tabular}{lcl}
\hline Parameter & Kisaran & Angka \\
& Penilaian \\
\hline Arus (cm/det) & $10-19$ dan $51-57$ & Baik \\
& $<10$ dan $>75$ & Sedang \\
& $15-25$ & Kurang \\
Kedalaman (m) & $5-15$ dan $26-35$ & Baik \\
& $<5$ dan $>35$ & Kedang \\
Oksigen Terlarut & $>6$ & Baik \\
(mg/l) & $4-6$ & Sedang \\
& $<4$ & Kurang \\
Kecerahan (m) & $>5$ & Baik \\
& $<-5$ & Sedang \\
Suhu $\left({ }^{0} \mathrm{C}\right)$ & $28-30$ & Kurang \\
& $25-27$ dan $31-32$ & Baik \\
& $<25$ dan $>32$ & Sedang \\
Salinitas (ppt) & $30-35$ & Kurang \\
& $20-29$ & Sedang \\
pH & $<20$ dan $>32$ & Kurang \\
& $6,5-8,5$ & Baik \\
& $4-6,4$ dan $8,5-9$ & Sedang \\
& $<4$ dan 9,5 & Kurang \\
\hline
\end{tabular}

(Selat P. Mahumu), Kec. Tabukan Selatan (Pesisir P. Tehang), Kec. Tabukan Selatan (muara Teluk Manalu), Kec. Tabukan Selatan (Teluk Manalu), Kec. Tabukan Selatan Tenggara (Pesisir Timur), dan Kec. Tabukan Tengah (Pesisir timur) dengan luas 792,89 Ha; rumput laut tersebar di 12 lokasi, yaitu Kec. Manganitu Selatan (Pesisir Barat P. Mahumu), Kec. Manganitu Selatan (Pesisir P. Batunderang), Kec. Manganitu Selatan (Pesisir P. Bebalang), Kec. Tabukan Selatan Tengah (Tonggeng Lingkusang), Kec. Tabukan Selatan Tenggara dan Kec. Manganitu Selatan (Pesisir Selatan), Kec. Tabukan Tengah dan Kec. Tabukan Selatan (Pesisir Timur), Kec. Tabukan Tengah dan Kec. Tabukan Utara (Pesisir Timur), Kec. Tabukan Tengah (Pesisir Timur), Kec. Tabukan Utara (Pesisir Timur), Kec. Tamako (Pesisir Barat), Kec. Tatoareng (Pesisir P. Kahakitang), Kec. Tatoareng (Pesisir P. Kalama) dengan luas 4.549,86 Ha; dan teripang di 3 lokasi, yaitu Kec. Manganitu (Pesisir Barat), Kec. Tabukan Selatan Tengah dan Kec. Tabukan Selatan (Pesisir Timur), Kec. Tabukan Tengah (Pesisir Timur) dengan luas 113,75 Ha.

Pemerintah Kab. Kep. Sangihe telah melakukan upaya pengembangan kawasan dengan menetapkan Peraturan Daerah Kepulauan Sangihe Nomor 4 Tahun 2011 tentang Rencana Tata Ruang Wilayah Kabupaten Kepulauan Sangihe 2011-2031 melalui 4 klaster pengembangan, yaitu: Klaster Kepulauan Marore, Nusa Tabukan, dan pulau-pulau sekitarnya; Klaster Tahuna dan sekitarnya, Klaster Teluk Dagho dan sekitarnya; dan Klaster Manalu dan sekitarnya (Anonim, 2011). Pusat pengembangan yang diarah-kan sebagai kawasan agropolitan dan minapolitan, sekaligus sebagai sentra budi daya kelautan/pesisir, adalah Klaster Manalu dan sekitarnya, yaitu kawasan Teluk Manalu, Kecamatan Tabukan Selatan, Tabukan Selatan Tenggara dan Tabukan Tengah.

Lingkungan dan parameter kualitas air untuk perikanan KJA laut sangat mempengaruhi berhasil atau tidaknya kegiatan budi daya yang akan dilakukan. Untuk itu, sebelum memulai kegiatan budi daya di suatu perairan, yang paling awal harus dilakukan adalah mengumpulkan data mengenai kelayakan lingkungan dan parameter kualitas air. Jika data yang diperoleh menunjukan, bahwa perairan tersebut layak maka kemungkinan usaha KJA dapat berhasil.

\section{MATERIAL DAN METODA}

Data yang dikumpulkan adalah data primer dan sekunder. Data primer, berupa data kualitas air, 
diperoleh dengan melakukan pengukuran dan pengambilan sampel pada empat lokasi (Lokasi 14), masing-masing tiga titik di Perairan Binebas, Hangke dan sekitarnya, yang dianggap mewakili keadaan perairan. Data sekunder, berupa data faktor kenyamanan dan faktor risiko, diperoleh melalui wawancara kepada orang yang dianggap mengenal keadaan perairan dan yang berhubungan langsung dengan kegiatan perikanan budi daya dengan KJA. Lokasi 1 terletak di depan kampung Hangke, Lokasi 2 di perairan sekitar Sensahang/Ensahange dan Talawe, Lokasi 3 di depan pantai Kalagheng, dan Lokasi 4 adalah perairan sekitar pantai Mutung dan Tanjung Bembiha. Pengambilan sampel dilakukan pada saat menjelang siang sampai dengan sore.

Data analisis kualitas air kemudian dibandingkan dengan penilaian kesesuaian parameter perairan untuk budi daya ikan laut dalam KJA (Tabel 1).

\section{HASIL DAN PEMBAHASAN}

Perairan sekitar Hangke, Sensahang/Ensahange, Talawe, Kalagheng, Mutung, dan Tanjung Bembiha merupakan perairan yang sangat terlindung dari gelombang dan angin sehingga tidak perlu mengkhawatirkan risiko terjadinya kerusakan pada KJA akibat kedua hal tersebut. Faktor keterlindungan merupakan hal utama yang menjadi pertimbangan dalam menentukan apakah sebuah lokasi layak dijadikan sebagai lahan budi daya. Beberapa orang masyarakat lokal telah melakukan usaha budi daya di sekitar perairan ini dan sampai saat ini penggunaannya sebagai lahan untuk usaha budi daya tidak menimbulkan konflik. Jarak tempuh antara lokasi penelitian dan tempat tinggal masyarakat berkisar 515 menit dan masih berada dalam jarak pandang dari rumah penduduk sehingga pengawasan dapat dengan mudah dilakukan. Pembudi daya lokal di sekitar perairan ini menggunakan Listrik Tenaga Surya (LTS) untuk menunjang aktivitas mereka di KJA. Komunikasi telah memadai dengan adanya jaringan telekomunikasi untuk pengguna hand phone.

\section{Salinitas}

Hasil pengamatan salinitas di perairan Hangke, Sensahang/Ensahange, Talawe, Kalagheng, Mutung, dan Tanjung Bembiha di 4 lokasi pengamatan berada pada kisaran 20,8-29,9 ppt. Salinitas rata-rata untuk Lokasi 1, yaitu 20,8 ppt; Lokasi 2, yaitu 24,8 ppt; Lokasi 3, yaitu 30,2 ppt; dan Lokasi 4, yaitu 29,9 ppt (Tabel 2).
Kisaran salinitas bervariasi dengan perbedaan hingga 10 ppt. Lokasi 1 dan 2 , yang berada pada posisi perairan yang masuk lebih jauh kedaratan, memiliki salinitas yang lebih rendah. Hal ini disebabkan karena terdapat sumber air tawar, berupa sungai kecil, dan mata air yang langsung masuk ke perairan. Lokasi 3 dan 4 berada pada posisi yang lebih dekat ke laut lepas sehingga lebih memperkecil pengaruh masukan air tawar. Menurut Nybakken (1988) dalam Patty (2013), dilihat dari sebaran, maka salinitas sekitar pantai lebih rendah dari pada salinitas laut lepas. Hal ini disebabkan karena air laut yang berada dekat daratan masih memiliki pengaruh dari air darat yang menyebabkan salinitas di daerah ini rendah. Sebaliknya, salinitas di perairan laut lepas tidak memiliki pengaruh dari darat sehingga salinitasnya pun besar.

Seperti telah diketahui, air tawar mempunyai nilai salinitas yang rendah, umumnya kurang dari $3 \%$, sedangkan air laut mempunyai nilai salinitas di atas $33 \%$. Aliran air sungai ke laut akan menimbulkan proses percampuran antara air sungai dan air laut. Dalam proses percampuran tersebut, nilai salinitas akan berkisar antara nilai salinitas air tawar dan salinitas air laut (Arief, 1984).

\section{Suhu}

Hasil pengamatan suhu perairan Hangke, Sensahang/Ensahange, Talawe, Kalagheng, Mutung dan Tanjung Bembiha di empat lokasi pengamatan berada pada kisaran $28,8{ }^{\circ} \mathrm{C}-29,1$ (Tabel 2). Data yang diperoleh memperlihatkan, bahwa perairan ini layak untuk menjadi lokasi budi daya ikan dengan KJA. Mayunar et al. (1995) dalam Affan (2012), suhu optimum untuk budi daya ikan ialah $27-32{ }^{\circ} \mathrm{C}$. Menurut Nybakken (1988) dalam Souhoka and Patty (2013), nilai suhu di lapisan permukaan laut yang normal berkisar $20-30{ }^{\circ} \mathrm{C}$.

\section{Oksigen Terlarut}

Hasil pengamatan di perairan Hangke, Sensahang/Ensahange, Talawe, Kalagheng, $\mathrm{Mu}-$ tung, dan Tanjung Bembiha di 4 lokasi pengamatan, oksigen terlarut terukuran pada kisaran 5,4-6,4 $\mathrm{mg} / \mathrm{l}$. Oksigen terlarut rata-rata untuk Lokasi 1 setinggi 5,4 mg/l; Lokasi 2 setinggi 5,5 mg/l; Lokasi 3 setinggi 5,8 mg/l; dan dan Lokasi 4 setinggi 6,4 $\mathrm{mg} / \mathrm{l}$ (Tabel 2).

Tingkat oksigen terlarut di ke empat perairan tersebut sangat layak untuk mendukung kehidupan dan pertumbuhan ikan-ikan yang akan dibudidayakan. Menurut Kordi (2005) dalam Ernawati and Dewi (2017), untuk pertumbuhan ikan-ikan laut dibutuhkan kandungan oksigen terlarut minimal 4 
$\mathrm{mg} / \mathrm{l}$; sedangkan kandungan optimumnya setinggi 5-6 mg/l. Sutamihardja (1978 dalam Souhoka and Patty, 2013) mengatakan, bahwa kadar oksigen di permukaan laut yang normal berkisar 5,7-8,5 mg/l.

\section{Kecerahan}

Hasil pengamatan kecerahan perairan Hangke, Sensahang/Ensahange, Talawe, Kalagheng, Mutung, dan Tanjung Bembiha di empat lokasi pengamatan berada pada kisaran 2,0-5,7 meter. Kecerahan rata-rata untuk Lokasi 1, 2, 3, dan 4, berturut-turut, sejauh $2 \mathrm{~m}, 2,4 \mathrm{~m}, 3,7 \mathrm{~m}$, dan 5,7 $\mathrm{m}$ (Tabel 2).

Data kecerahan yang diperoleh memperlihatkan, bahwa untuk Lokasi 1 dan 2 memiliki kecerahan yang kurang. Perairan tersebut terlihat sangat keruh, hal ini disebabkan oleh karena substrat dasar perairan yang berlumpur. Lokasi ini menjadi kurang layak untuk dijadikan sebagai lokasi budi daya dengan KJA. Lokasi 3 dan 4 memiliki kecerahan yang layak menjadi lokasi budi daya dengan KJA. Hal ini disebabkan karena kedua lokasi ini memiliki substrat dasar perairan karangberpasir. Landau (1995 dalam Adipu et al., 2013) menyatakan, bahwa untuk kegiatan budi daya ikan di KJA, kekeruhan yang tinggi dapat berakibat terganggunya proses osmoregulasi dalam tubuh ikan, menurunkan daya lihat, dan terganggunya fungsi insang, dan menurunkan tingkat respirasi atau per- nafasan, serta memicu pembentukan bio-fouling pada struktur KJA sehingga meningkatkan daya statis dan dinamis dari sistem KJA.

\section{Derajat Keasaman (pH)}

Hasil pengamatan di perairan Hangke, Sensahang/Ensahange, Talawe, Kalagheng, Mutung, dan Tanjung Bembiha di empat lokasi pengamatan menunjukkan tingkat keasaman $(\mathrm{pH})$ berada pada kisaran 6,8-7 (Tabel 2). Rerata $\mathrm{pH}$ untuk Lokasi 1, 2, 3, dan 4, berturut-turut, setinggi $6,9,6,8,7$, dan 7. Ke empat lokasi tersebut memiliki tingkat $\mathrm{pH}$ yang cocok sebagai lokasi budi daya ikan dengan KJA. Mayunar et al. (1995 dalam Affan, 2011) menyebutkan, bahwa pH optimal untuk budi daya ikan adalah 6,5-9,0. Tingkat $\mathrm{pH}$ sangat berpengaruh terhadap pertumbuhan dan kelangsungan hidup ikan di mana pada $\mathrm{pH}$ rendah (bersifat asam; $\mathrm{pH}<5$ ) dan $\mathrm{pH}$ tinggi (bersifat basa, $\mathrm{pH}>11$ ) dapat menimbul-kan mortalitas ikan dan tidak terjadi reproduksi (Affan, 2011).

\section{Kedalaman}

Di perairan tempat lokasi penelitian, pada ke empat lokasi pengamatan menunjukkan kisaran kedalaman bervariasi, yaitu 3,4-9 $\mathrm{m}$ (Tabel 2). Kedalaman rata-rata untuk Lokasi 1, 2, 3, dan 4, berturut-turut, sedalam 3,4 m, $4 \mathrm{~m}, 6,3 \mathrm{~m}$, dan $9 \mathrm{~m}$.

Data kedalaman perairan Hangke, Sensa-

Tabel 2. Penilaian kesesuaian kondisi perairan di Perairan Hangke, Sensahang/Ensahange, Talawe, Kalagheng, Mutung, dan Tanjung Bembiha

\begin{tabular}{|c|c|c|c|c|c|c|}
\hline \multirow{2}{*}{ Parameter } & \multirow{2}{*}{ Kisaran } & \multirow{2}{*}{$\begin{array}{c}\text { Angka } \\
\text { Penilaian }\end{array}$} & \multicolumn{4}{|c|}{ Lokasi } \\
\hline & & & 1 & 2 & 3 & 4 \\
\hline \multirow{3}{*}{ Salinitas (ppt) } & $30-35$ & Baik & & & & \\
\hline & $20-29$ & Sedang & 20,8 & 24,8 & 30,19 & 29,9 \\
\hline & $<20$ dan $>32$ & Kurang & & & & \\
\hline \multirow{3}{*}{ Suhu $\left({ }^{0} \mathrm{C}\right)$} & $28-30$ & Baik & 28,9 & 28,8 & 29,1 & 29 \\
\hline & $25-27$ dan $31-32$ & Sedang & & & & \\
\hline & $<25$ dan $>32$ & Kurang & & & & \\
\hline \multirow{3}{*}{ Oksigen Terlarut (mg/l) } & $>6$ & Baik & & & & 6,4 \\
\hline & $4-6$ & Sedang & 5,4 & 5,5 & 5,8 & \\
\hline & $<4$ & Kurang & & & & \\
\hline \multirow{3}{*}{ Kecerahan (m) } & $>5$ & Baik & & & & 5,7 \\
\hline & $3-5$ & Sedang & & & 3,7 & \\
\hline & $<3$ & Kurang & 2 & 2,4 & & \\
\hline \multirow{4}{*}{$\mathrm{pH}$} & $6,5-8,5$ & Baik & 6,9 & 6,8 & 7 & 7 \\
\hline & $4-6,4$ dan $8,5-9$ & Sedang & & & & \\
\hline & $<4$ dan 9,5 & Kurang & & & & \\
\hline & $15-25$ & Baik & & & & \\
\hline \multirow[t]{2}{*}{ Kedalaman (m) } & $5-15$ dan $26-35$ & Sedang & & & 6,3 & 9 \\
\hline & $<5$ dan $>35$ & Kurang & 3,4 & 4 & & \\
\hline \multirow{3}{*}{$\begin{array}{l}\text { Kecepatan Arus } \\
\text { (cm/det) }\end{array}$} & $20-50$ & Baik & & & 23,95 & 26,2 \\
\hline & $10-19$ dan $51-57$ & Sedang & 14,31 & 13,9 & & \\
\hline & $<10$ dan $>75$ & Kurang & & & & \\
\hline
\end{tabular}


hang/Ensahange, Talawe, Kalagheng, Mutung, dan Tanjung Bembiha memperlihatkan, bahwa untuk Lokasi 1 dan 2 terlalu dangkal untuk menjadi lokasi budi daya ikan dengan konstruksi KJA sehingga dikategorikan "kurang layak". Lokasi 3 dan 4 dapat menjadi lokasi budi daya ikan dengan KJA.

DKP (2003 dalam Heriansah and Anggriawan, 2015) menyatakan, bahwa kedalaman perairan $<5 \mathrm{~m}$ adalah "kurang baik" untuk dilakukan kegiatan budi daya, dan untuk kedalaman 5-15 m penilaiannya "sedang". Menurut Kordi (2005 dalam Ernawati and Dewi, 2017), nilai kedalaman perairan berkisar 7-15 $\mathrm{m}$ dari permukaan hingga ke dasar perairan atau kedalaman minimal $1 \mathrm{~m}$ dari keramba sampai ke dasar perairan masih layak untuk budi daya laut. Menurut Adipu et al. (2013), untuk budi daya ikan dalam KJA, kedalaman perairan yang minimal ditentukan oleh dimensi kantong jaring, beda pasang surut, dan jarak minimal antar kantong dan dasar perairan. Menyiasati perairan dangkal dapat dilakukan dengan cara mengurangi tinggi kantong jaring sehingga dapat diperoleh jarak karamba ke dasar perairan sebesar $1 \mathrm{~m}$.

\section{Kecepatan Arus}

Hasil pengamatan kecepatan arus di perairan Hangke, Sensahang/Ensahange, Talawe, Kalagheng, Mutung, dan Tanjung Bembiha di empat lokasi pengamatan, berada pada kisaran 13,9-26,2 $\mathrm{cm} /$ det (Tabel 2). Kecepatan arus rata-rata untuk Lokasi 1, 2, 3, dan 4 berturut-turut sebesar 14,31 $\mathrm{cm} /$ det, 13,9 cm/det, 23,95 cm/det, dan 26,2 cm/det.

Kecepatan arus di Lokasi 1 dan 2 termasuk dalam kategori "sedang" untuk budi daya ikan dengan KJA; sedangkan Lokasi 3 dan 4 memiliki kecepatan arus yang "baik" untuk kegiatan budi daya ikan dengan KJA. Menurut DKP (2002 dalam Heriansah and Anggriawan, 2015), kecepatan arus $10-19 \mathrm{~cm} /$ det termasuk dalam kategori "sedang" dan kecepatan arus 20-50 cm/det termasuk kategori "baik". Mayunar et al. (1995 dalam Affan, 2012), bahwa organisme penempel akan lebih banyak pada jaring apabila kecepatan arus di bawah $25 \mathrm{~cm} / \mathrm{dt}$ sehingga akan mengurangi sirkulasi air dan oksigen terlarut, namun kecepatan arus yang baik untuk budi daya dalam KJA adalah berkisar 5-15 cm/det.

\section{KESIMPULAN}

Dapat disimpulkan, bahwa perairan di lokasi penelitian nyaman dan tidak berisiko untuk dijadikan lokasi budi daya. Berdasarkan evaluasi terhadap parameter kualitas air di perairan Hangke,
Sensahang/Ensahange, Talawe, Kalagheng, Mutung, dan Tanjung Bembiha menunjukan, bahwa Lokasi 3 dan 4 "layak" untuk menjadi lokasi perikanan budi daya KJA dan dapat dikembangkan lebih lanjut.

\section{REFERENSI}

ADIPU, Y., LUMENTA, C., KALIGIS, E. and SINJAL, H.J. (2013). Kesesuaian Lahan Budi daya Laut di Kabupaten Bolaang Mangondow Selatan, Sulawesi Utara. Jurnal Perikanan dan Kelautan Tropis, 9(1).

AFFAN, J.M. (2011) Seleksi Lokasi Pengembangan Budi daya Dalam Keramba Jaring Apung (KJA) Berdasarkan Faktor Lingkungan Dan Kualitas Air Di Perairan Pantai Timur Kabupaten Bangka Tengah. J. Sains MIPA, 17(3), 99-106.

AFFAN, J.M. (2012) Identifikasi lokasi untuk pengembangan budi daya keramba jaring apung (KJA) berdasarkan faktor lingkungan dan kualitas air di perairan Pantai Timur Bangka Tengah. Banda Aceh: Depik.

ANONIM (2015) RZWP3K Kabupaten Kepu-Lauan Sangihe. Kementerian Kelautan Dan Perikanan Direktorat Jenderal Kelautan, Pesisir, Dan Pulau-Pulau Kecil. Satuan Kerja Direktorat Tata Ruang Laut, Pesisir, Dan Pulau-Pulau Kecil.

ANONIM (2011) Peraturan Daerah Kabupaten Kepulauan Sangihe Nomor 4 tahun 2011 tentang Rencana Tata Ruang Wilayah Kabupaten Kepulauan Sangihe 2011-2031.

ERNAWATI, A.P. and DEWI, W.K. (2017) Kajian Kesesuaian Kualitas Air Untuk Pengembangan Keramba Jaring Apung Di Pulau Serangan, Bali. Denpasar: Universitas Udayana.

HERIANSAH and ANGGRIAWAN, F. (2015) Penentuan Kelayakan Lokasi Keramba Jaring Apung Kerapu (Epinephelus Spp) Melalui Sistem Informasi Geografis Di Pulau Saugi Kabupaten Pangkep Provinsi Sulawesi Selatan.

PATTY, S.I. (2013) Distribusi Suhu, Salinitas Dan Oksigen Terlarut Di Perairan Kema, Sulawesi Utara. Jurnal Ilmiah Platax.

SOUHOKA, J. and PATTY, S. (2013) Pemantauan Kondisi Hidrologi Dalam Kaitannya Dengan Kondisi Terumbu Karang Di Perairan Pulau Talise, Sulawesi Utara. Jurnal Ilmiah Platax, 1(3).

Received: 20 July 2018 Accepted: 25 September 2018 